\title{
Calotropis procera Latex-Induced Inflammatory Hyperalgesia-Effect of Antiinflammatory Drugs
}

\author{
Raman Sehgal and Vijay L. Kumar \\ Department of Pharmacology, All India Institute of Medical Sciences, Ansari Nagar, New Delhi 110029, India
}

Received 11 April 2005; accepted 17 May 2005

\begin{abstract}
The milky white latex of plant Calotropis procera produces inflammation of the skin and mucous membranes on accidental exposure. It produces edema on local administration due to the release of histamine and prostaglandins and is associated with hyperalgesia. In the present study we have evaluated the antiedematous and analgesic activity of antiinflammatory drugs against inflammatory response induced by dried latex (DL) of $C$ procera in rat paw edema model. An aqueous extract of DL of $C$ procera was injected into the subplantar surface of the rat paw and the paw volume was measured by a plethysmometer at $0,1,2,6,12$, and 24 hours. Concomitantly the hyperalgesic response was also evaluated by motility test, stair climbing ability test, dorsal flexion pain test, compression test, and observing the grooming behavior. The inhibitory effect of diclofenac and rofecoxib on edema formation and hyperalgesic response was compared with cyproheptadine $(\mathrm{CPH})$. DL-induced edema formation was maximum at 2 hours that was associated with decreased pain threshold, functional impairment, and grooming. Treatment with antiinflammatory drugs and CPH significantly attenuated the edematous response and grooming, increased the pain threshold, and improved functional parameters. Both antiinflammatory and antiserotonergic drugs significantly inhibited the hyperalgesia associated with DL-induced paw edema. Rofecoxib was found to be superior than diclofenac and was as effective as $\mathrm{CPH}$ in ameliorating the hyperalgesia. However, it was found to be less effective than $\mathrm{CPH}$ in attenuating edema formation.
\end{abstract}

\section{INTRODUCTION}

Calotropis procera (Ait) $\mathrm{R} \mathrm{Br}$, a plant of family Asclepiadaceae, is well known for its medicinal as well as toxic properties $[1,2]$. The plant produces milky white latex that exhibits pleiotropic effects in various animal models [3]. On oral administration, the latex produces potent antiinflammatory, analgesic, and weak antipyretic effects, while on local administration it induces intense inflammatory response $[4,5,6,7]$. Even the accidental exposure to the latex produces contact dermatitis, keratitis, and toxic iridocyclitis $[8,9,10]$. The acute inflammation induced by latex involves edema formation and cellular infiltration that has been attributed to the presence of histamine in the latex and the release of mast cell histamine $[7,11]$. Besides, the latex has also been shown to induce prostaglandin (PG) synthesis through the induction of cyclooxygenase-2 (COX-2) [12]. Both histamine and PGs are the key mediators in an inflammatory response and play a significant role in inflammatory hyperalgesia along with various other mediators $[13,14]$. These inflammatory mediators activate local pain receptors (ie, nociceptors) and nerve terminals that produce hypersensitivity

Correspondence and reprint requests to Vijay L. Kumar, Department of Pharmacology, All India Institute of Medical Sciences, Ansari Nagar, New Delhi 110029, India; kumarv198@hotmail.com in the area of injury as observed in various inflammatory conditions $[15,16]$.

Studies carried out in various acute and chronic models of inflammation demonstrate that cyproheptadine $(\mathrm{CPH})$, celecoxib, and phenylbutazone significantly inhibit inflammatory response elicited by the latex of $C$ procera, however, $\mathrm{CPH}$ is most effective in this regard [11]. Besides inhibiting inflammation, these drugs are also known to produce analgesic effect [17, 18, 19]. In the present study, we have evaluated the effect of antiinflammatory drugs, rofecoxib and diclofenac, against inflammatory hyperalgesia induced by latex of $C$ procera in paw edema model and compared it with $\mathrm{CPH}$. A battery of tests were performed to evaluate the effect of these drugs on edema formation, motility, stair climbing ability (SCA), pain associated with dorsal flexion, compression, and behavioral parameter, that is, grooming $[20,21]$.

\section{MATERIALS AND METHODS}

\section{Plant material and drugs}

The latex of $C$ procera was collected from the aerial parts of the plant growing in the wild and was dried under shade (DL). It was then triturated in normal saline (NS) and centrifuged to obtain a clear solution. The plant was identified by the Raw Materials, Herbarium, and Museum Division, National Institute of Science and 
Communication, New Delhi, where a voucher specimen is preserved (Voucher no PID 1739). The drugs used in this study were obtained from Merind India Ltd (Mumbai, Maharashtra, India) (Cyproheptadine) and Arbro Pharmaceuticals (New Delhi, India) (Diclofenac and Rofecoxib).

\section{Animals}

The study was carried out on male Wistar rats weighing $150-180 \mathrm{~g}$. They were kept at ambient temperature and had free access to water and diet. All experimental procedures described were carried out in accordance with the guidelines of Institutional Animal Ethics Committee.

\section{Induction of paw edema by $D L$}

Edema was induced in the right hind paw of rats by injecting $0.1 \mathrm{~mL}$ of $1 \%$ solution of $\mathrm{DL}$ and paw volume was measured upto a fixed mark on the lateral malleolus at $0,1,2,6,12$, and 24 hours using a plethysmometer. Edema volume was calculated at each time interval as the difference from paw volume at 0 hour. Cyproheptadine (10 mg/kg; CPH10), diclofenac (10 and $100 \mathrm{mg} / \mathrm{kg}$; Diclo10 and Diclo100) and rofecoxib (15 and $100 \mathrm{mg} / \mathrm{kg}$; Rofe15 and Rofe100) were administered orally as suspension with 5\% gum acacia in NS 1 hour before injecting DL. The effect of antiinflammatory drugs at each time interval was evaluated on the stair climbing ability, motility, grooming behavior, and pain produced by dorsal flexion and compression.

\section{Stair climbing ability test}

The overnight fasted animals were trained for one week to climb a staircase with steps at 5,10 , and $15 \mathrm{~cm}$ having water at the second and food at the third step $[20,21]$. The climbing ability of the rats in the above groups was scored 0 if the rats did not climb; 1 , if the rats climbed onto step $1 ; 2$, if the rats climbed upto step 2 ; and 3 , if the rat could climb all the three steps.

\section{Motility test}

The motility pattern of the rats was observed for a period of 5 minutes and scored 0 , if the rat avoided touching the inflamed paw to the floor while walking; 1, if the rat walked with little difficulty, but the toe touched the floor; and 2 , if the rat walked easily $[20,21]$.

\section{Dorsal flexion pain test}

The ankle joint was flexed dorsally until the toe touched the anterior part of the leg. The test was performed five times with an intertest interval of 5 seconds and the pain was scored 0 , if there was no squeaking and no leg withdrawal; 1 , if there was either squeaking or leg withdrawal; and 2, if both squeaking and leg withdrawal were present [20].

\section{Compression test}

The thickness of inflamed paw was measured by the micrometer screw gauze and the paw was compressed by

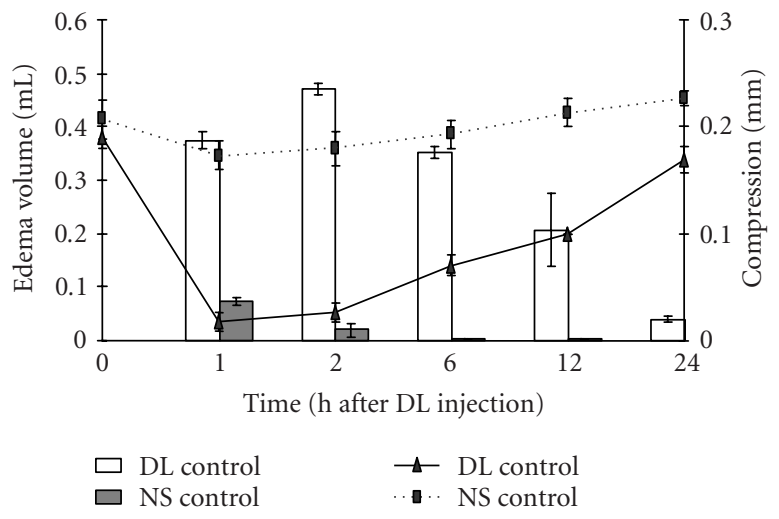

Figure 1. Time course for DL-induced edema formation and extent of compression required to elicit pain in rat paw. Aqueous solution of DL of C procera ( $0.1 \mathrm{~mL}$ of $1 \%$ solution) and NS $(0.1 \mathrm{~mL})$ were injected into the subplantar surface of the rat paw and edema volume and compression were measured at 1, 2, 6, 12 , and 24 hours $(n=6)$. Bars indicate edema volume and lines indicate compression to elicit pain.

rotating the screw till pain was elicited as indicated by squeaking or leg withdrawal. The distance moved by the screw gauze was recorded.

\section{Grooming behavior}

The rats were observed for 10 minutes and the number of grooming was recorded [20].

\section{Statistical analysis}

The values for edema volume, compression, and grooming are expressed as mean \pm standard error of the mean of six observations and student's $t$ test was used to compare the groups. The stair climbing ability test, motility, and pain following dorsal flexion are expressed as median scores and Kruscal-Wallis test was used to compare the groups. The statistical analysis was carried out by the version 10 of the SPSS programme and the values of $P<.05$ was considered as statistically significant.

\section{RESULTS}

Subplantar injection of aqueous solution of DL of $C$ procera produced an edematous response with peak edema occurring at 2 hours whereas NS produced a marginal increase in paw volume at first hour that was equivalent to the volume of NS injected (Figure 1). Figure 1 also shows that the pain threshold in DL-treated paw was much lower as compared to NS-treated paw and the paw could be compressed only by $0.03 \pm 0.01 \mathrm{~mm}$ against $0.18 \pm 0.02 \mathrm{~mm}$ in NS control group. As the inflammation declined, the extent of compression required to elicit pain increased. We further studied the antiedematous effect of various drugs in paw edema model at 2 hours. Both diclofenac and rofecoxib produced a dose-dependent effect and the edema volume was $0.22 \pm 0.002 \mathrm{~mL}$ and 


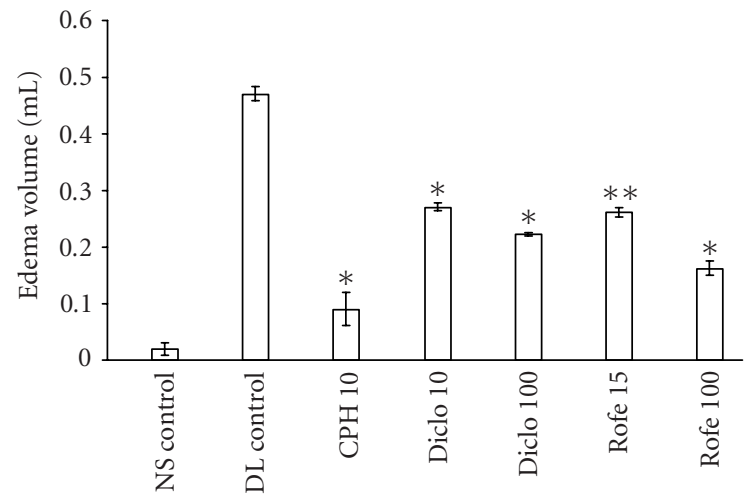

Figure 2. Antiinflammatory effect of various drugs on DLinduced paw edema. Edema was induced by injecting $0.1 \mathrm{~mL}$ of $1 \%$ solution of DL into subplantar surface of right hind paw. The drugs were administered orally 1 hour before injecting DL. Edema volume was measured at 2 hours $(n=6)$. CPH 10-cyproheptadine $10 \mathrm{mg} / \mathrm{kg}$; Diclo 10-diclofenac $10 \mathrm{mg} / \mathrm{kg}$; Diclo 100 -diclofenac $100 \mathrm{mg} / \mathrm{kg}$; Rofe 15-rofecoxib $15 \mathrm{mg} / \mathrm{kg}$; Rofe 100 -rofecoxib $100 \mathrm{mg} / \mathrm{kg} ;{ }^{*} P<.01$ and ${ }^{* *} P<.05$ versus DL control.

$0.16 \pm 0.01 \mathrm{~mL}$ in Diclo 100 and Rofe 100 groups against $0.47 \pm 0.01 \mathrm{~mL}$ in $\mathrm{DL}$ control. CPH was most effective in this regard and the edema volume in $\mathrm{CPH}$-treated rats was $0.09 \pm 0.03 \mathrm{~mL}$ (Figure 2).

As inflammation is usually associated with hyperalgesia, the effect of various drugs was also evaluated on the pain threshold. Both diclofenac and rofecoxib produced a dose-dependent effect and the paw could be compressed upto $0.09 \pm 0.01 \mathrm{~mm}$ and $0.12 \pm 0.01 \mathrm{~mm}$ as against $0.03 \pm 0.01 \mathrm{~mm}$ in DL control. The effect of $\mathrm{CPH} 10$ was similar to that of Diclo100 (Table 1). The inflammatory pain induced by DL was found to be associated with grooming (11.4 \pm 0.75$)$ while NS control group did not exhibit any grooming. Treatment of rats with diclofenac and rofecoxib significantly decreased the number of grooming activity to $4.50 \pm 0.50$ and $4.00 \pm 0.41$ while it was $5.80 \pm 0.85$ in $\mathrm{CPH}$-treated group (Table 1 ).

The effect of these drugs was further evaluated on the pain produced by the flexion of the inflamed paw. The time course study was carried out and a maximum median score of 9.5 was obtained at 1 hour following DL injection and the pain persisted upto 24 hours. CPH was found to be most effective in decreasing the pain response as compared to diclofenac and rofecoxib and a score of 4,6 , and 5.5, respectively, was obtained after 1 hour $(P<$ .01) (Figure 3).

We further tested the ability of the animals to move and to climb staircase at the time of peak inflammation. The animals in the DL control group exhibited a score of 0 with respect to motility and stair climbing ability whereas the animals in the NS control group exhibited a maximum motility score of 2 and stair climbing ability score of 3. Both diclofenac and rofecoxib improved the motility and stair climbing ability in a dose-dependent manner and rats in Rofe100 group could climb all the three steps

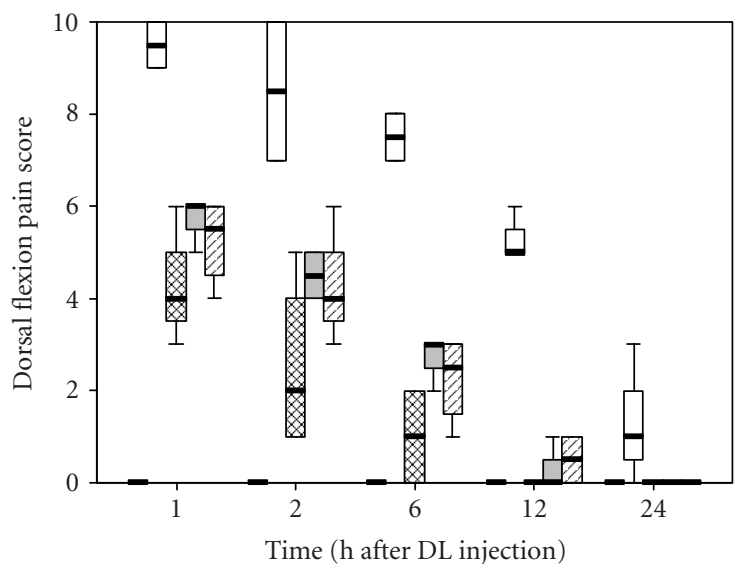

NS control
$\square$ DL control
$\square$ Cyproheptadine $10 \mathrm{mg} / \mathrm{kg}$

$\square$ Diclofenac $100 \mathrm{mg} / \mathrm{kg}$ [7] Rofecoxib $100 \mathrm{mg} / \mathrm{kg}$

Figure 3. Antihyperalgesic effect of various drugs on DLinduced inflammatory hyperalgesia. Edema was induced by injecting $0.1 \mathrm{~mL}$ of $1 \%$ solution of DL into subplantar surface of right hind paw. The drugs were administered orally 1 hour before injecting DL. Dorsal flexion pain score was recorded at 1 , $2,6,12$, and 24 hours $(n=6)$. The data is illustrated as box plots where bold line represents median values, boxes represent interquartile ranges (25th and 75th percentiles), and whiskers represent extreme values.

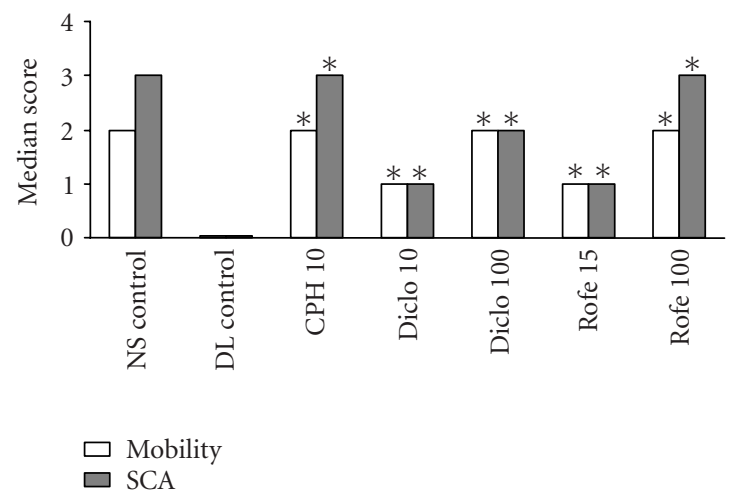

FIgURE 4. Effect of various drugs on DL-induced motility impairment and staircase climbing ability (SCA). Edema was induced by injecting $0.1 \mathrm{~mL}$ of $1 \%$ solution of DL into subplantar surface of right hind paw. The drugs were administered orally 1 hour before injecting DL. Motility and staircase climbing ability were observed at 2 hours $(n=6) .{ }^{*} P<.01$ versus DL control.

and their motility score was 2 while rats in Diclo100 group could climb up to step 2 even though they did not have any difficulty in motility. CPH at a dose of $10 \mathrm{mg} / \mathrm{kg}$ was as effective as $100 \mathrm{mg} / \mathrm{kg}$ dose of rofecoxib (Figure 4).

\section{DISCUSSION}

In the present study we have evaluated the effect of antiinflammatory drugs on the inflammatory hyperalgesia induced by latex of $C$ procera, when injected into the 
TABLE 1. Effect of various drugs on DL-induced inflammatory hyperalgesia and associated behavioral changes. Edema was induced by injecting $0.1 \mathrm{~mL}$ of $1 \%$ solution of DL into subplantar surface of right hind paw. The drugs were administered orally 1 hour before injecting DL. Extent of compression and number of groomings were recorded at 2 hours. The values given are mean \pm standard error of the mean $(n=6)$.

\begin{tabular}{lcc}
\hline Treatment groups & Compression $(\mathrm{mm})$ & Groomings (number) \\
\hline NS control & $0.18 \pm 0.02$ & - \\
DL control & $0.03 \pm 0.01$ & $11.40 \pm 0.75$ \\
Cyproheptadine $(10 \mathrm{mg} / \mathrm{kg})$ & $0.09 \pm 0.01^{*}$ & $5.82 \pm 0.85^{*}$ \\
Diclofenac $(10 \mathrm{mg} / \mathrm{kg})$ & $0.07 \pm 0.01^{*}$ & $7.50 \pm 0.65^{*}$ \\
Diclofenac $(100 \mathrm{mg} / \mathrm{kg})$ & $0.09 \pm 0.01^{*}$ & $4.50 \pm 0.50^{*}$ \\
Rofecoxib $(15 \mathrm{mg} / \mathrm{kg})$ & $0.07 \pm 0.01^{*}$ & $7.50 \pm 0.29^{*}$ \\
Rofecoxib $(100 \mathrm{mg} / \mathrm{kg})$ & $0.12 \pm 0.00^{*}$ & $4.00 \pm 0.41^{*}$ \\
\hline
\end{tabular}

$* P<.05$ versus DL control.

paw. Subplantar injection of aqueous solution of DL produced intense inflammatory response with a peak effect occurring at 2 hours. This was associated with hyperalgesia that was maximum between 1-2 hours and a slight compression of the inflamed paw caused leg withdrawal and squeaking. Subsequently as the inflammation subsided, the extent of compression required to elicit pain also increased. As reported earlier, the inflammatory response induced by DL is brought about by the histamine present in it and also by the release of endogenous histamine from mast cells [11].

Edema and pain are characteristic signs of an inflammatory response where the role of prostaglandins and histamine is well established [13]. Prostaglandins are endogenous mediators of inflammation and are generated from arachidonic acid by the action of cyclooxygenase (COX) that exists in two isoforms, COX-1 and COX-2. COX-1 is constitutive whereas COX-2 is the cytokine inducible form of the enzyme. We have evaluated the effect of diclofenac, a nonselective COX inhibitor, and rofecoxib, a COX-2 selective inhibitor, on inflammatory hyperalgesia induced by DL and compared it with $\mathrm{CPH}$ that has been shown to effectively inhibit DL-induced inflammation [11]. Although, diclofenac and rofecoxib produced a dose-dependent decrease in edema formation, they were not as effective as $\mathrm{CPH}$. $\mathrm{CPH}$ inhibits the preformed histamine and serotonin that are released early in an inflammatory response while PG are synthesized late and their maximum levels are attained between 312 hours after induction of inflammation $[13,22] . \mathrm{CPH}$ produced a significant decrease in inflammatory hyperalgesia as revealed by compression test, dorsal flexion pain test and grooming activity. The analgesic effect of $\mathrm{CPH}$ could be mainly due to its ability to inhibit the action of histamine, serotonin, and bradykinin, all of which are key mediators of inflammatory hyperalgesia [13, 23]. Both diclofenac and rofecoxib were also effective as analgesics even though their antiedematous effect was less as compared to CPH. Further, rofecoxib was found to be slightly more effective than diclofenac. The greater efficacy of rofecoxib as compared to diclofenac in relieving acute pain has also been reported by Desjardins et al [24]. The hypoalgesic effect of COX inhibitors has been attributed to the selective inhibition of COX-2 and is brought about at doses that may not cause reduction in edema volume [25]. It may also be due to selective inhibition of COX-2 in the dorsal horn neurons of the spinal cord that contributes to the nociceptive processing [26]. The efficacy of antiinflammatory drugs against DL-induced inflammatory hyperalgesia was further substantiated by their ability to improve motility and stair climbing ability.

Thus, our study indicates that edema formation induced by DL could be effectively inhibited by $\mathrm{CPH}$ whereas the associated inflammatory hyperalgesia is inhibited equally by both CPH and rofecoxib.

\section{REFERENCES}

[1] CSIR Publication and Information Directorate. Wealth of India: Raw materials. III. New Delhi, India: CSIR Publication and Information Directorate; 1992;78-84.

[2] Mahmoud OM, Adam SE, Tartour G. The effects of Calotropis procera on small ruminants II. Effects of administration of the latex to sheep and goats. $J$ Comp Pathol. 1979;89(2):251-263.

[3] Kumar VL, Arya S. Medicinal uses and pharmacological properties of Calotropis procera. Recent Prog Med Plants. In press.

[4] Majumder PK, Kumar VL. Anti-inflammatory activity of fractions of latex of Calotropis procera in carrageenin induced paw oedema. Phytother Res. 1997;11:166-167.

[5] Dewan S, Sangraula H, Kumar VL. Preliminary studies on the analgesic activity of the latex of Calotropis procera. J Ethnopharmacol. 2000;73(1-2):307-311.

[6] Dewan S, Kumar S, Kumar VL. Antipyretic effect of latex of Calotropis procera. Ind J Pharmacol. 2000;32(3):252.

[7] Singh H, Kumar S, Dewan S, Kumar VL. Inflammation induced by latex of Calotropis procera-a new 
model to evaluate anti-inflammatory drugs. J Pharmacol Toxicol Methods. 2000;43(3):219-224.

[8] Handa F, Sadana JK, Sharma PK. Allergic contact dermatitis due to the plant of Calotropis procera (Vern: AK). A case report. Ind J Dermatol. 1984;29(3):27-29.

[9] Al-Mezaine HS, Al-Rajhi AA, Al-Assiri A, Wagoner MD. Calotropis procera (ushaar) keratitis. Am J Ophthalmol. 2005;139(1):199-202.

[10] Biedner B, Rothkoff L, Witzium A. Calotropis procera (Sodom apple) latex keratoconjunctivitis. Isr J Med Sci. 1977;13(9):914-916.

[11] Shivkar YM, Kumar VL. Histamine mediates the pro-inflammatory effect of latex of Calotropis procera in rats. Mediators Inflamm. 2003;12(5):299-302.

[12] Kumar VL, Shivkar YM. Involvement of prostaglandins in inflammation induced by latex of Calotropis procera. Mediators Inflamm. 2004;13(3):151-155.

[13] Di Rosa M, Giroud JP, Willoughby DA. Studies on the mediators of the acute inflammatory response induced in rats in different sites by carrageenan and turpentine. J Pathol. 1971;104(1):15-29.

[14] Guay J, Bateman K, Gordon R, Mancini J, Riendeau D. Carrageenan-induced paw edema in rat elicits a predominant prostaglandin E2 (PGE2) response in the central nervous system associated with the induction of microsomal PGE2 synthase-1. J Biol Chem. 2004;279(23):24866-24872.

[15] Juan H. Dependence of histamine-evoked nociception on prostaglandin release. Agents Actions. 1981;11(6-7):706-710.

[16] Ferreira SH. The role of interleukins and nitric oxide in the mediation of inflammatory pain and its control by peripheral analgesics. Drugs. 1993;46(1):1-9.

[17] Harris RR, Black L, Surapaneni S, et al. ABT-963[2-(3,4-difluoro-phenyl)-4-(3-hydroxy-3methyl-butoxy)-5-(4-methanesulfonyl-phenyl)-2Hpyridazin-3-one], a highly potent and selective disubstituted pyridazinone cyclooxgenase- 2 inhibitor. J Pharmacol Exp Ther. 2004;311(3):904-912.

[18] De Campos RO, Alves RV, Kyle DJ, Chakravarty S, Mavunkel BJ, Calixto JB. Antioedematogenic and antinociceptive actions of NPC 18521, a novel bradykinin B2 receptor antagonist. Eur J Pharmacol. 1996;316(2-3):277-286.

[19] Lomen PL, Turner LF, Lamborn KR, Brinn EL, Sattler LP . Flurbiprofen in the treatment of ankylosing spondylitis. A comparison with phenylbutazone. Am J Med. 1986;80(3A):120-126.

[20] De Castro Costa M, De Sutter P, Gybels J, Van Hees J. Adjuvant-induced arthritis in rats: a possible animal model of chronic pain. Pain. 1981;10(2):173-186.

[21] Wang Y, Huang C, Cao Y, Han JS. Repeated administration of low dose ketamine for the treatment of monoarthritic pain in the rat. Life Sci. 2000;67(3):261-267.
[22] Capasso F, Dunn CJ, Yamamoto S, Willoughby DA, Giroud JP. Further studies on carrageenan-induced pleurisy in rats. J Pathol. 1975;116(2):117-124.

[23] Reylon V, Siddiqui HH. Anti-spasmogenic effect of cyproheptadine on guinea-pig ileum. Indian J Physiol Pharmacol. 1983;27(4):342-344.

[24] Desjardins PJ, Black PM, Daniels S, et al. A randomized controlled study comparing rofecoxib, diclofenac sodium, and placebo in post-bunionectomy pain. Curr Med Res Opin. 2004;20(10):1523-1537.

[25] Francischi JN, Chaves CT, Moura AC, et al. Selective inhibitors of cyclo-oxygenase-2 (COX-2) induce hypoalgesia in a rat paw model of inflammation. $\mathrm{Br} J$ Pharmacol. 2002;137(6):837-844.

[26] Burian M, Tegeder I, Seegel M, Geisslinger G. Peripheral and central antihyperalgesic effects of diclofenac in a model of human inflammatory pain. Clin Pharmacol Ther. 2003;74(2):113-120. 


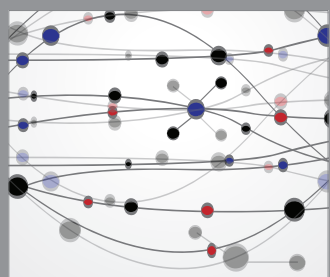

The Scientific World Journal
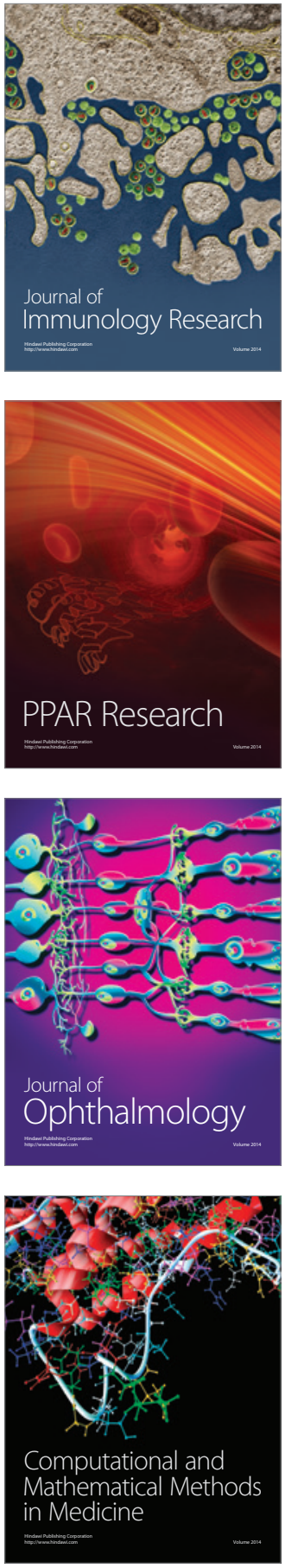

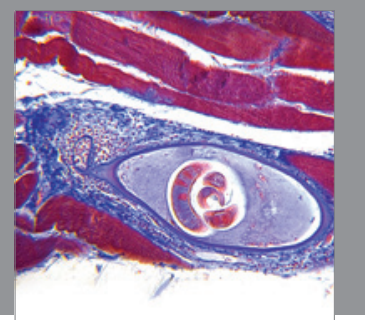

Gastroenterology

Research and Practice
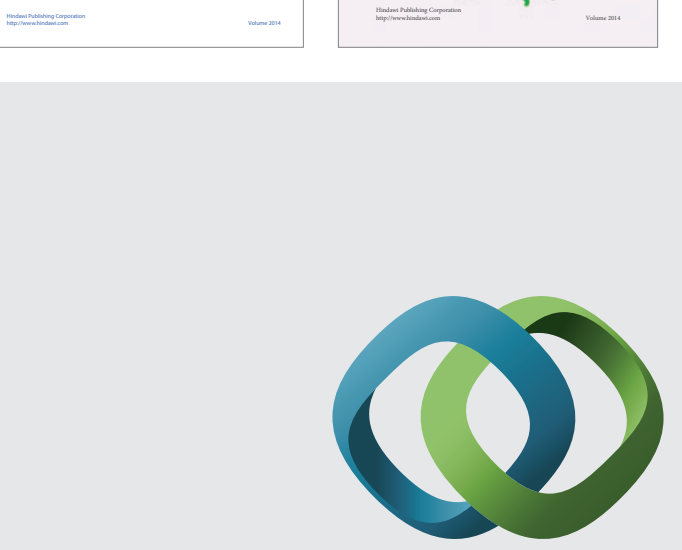

\section{Hindawi}

Submit your manuscripts at

http://www.hindawi.com
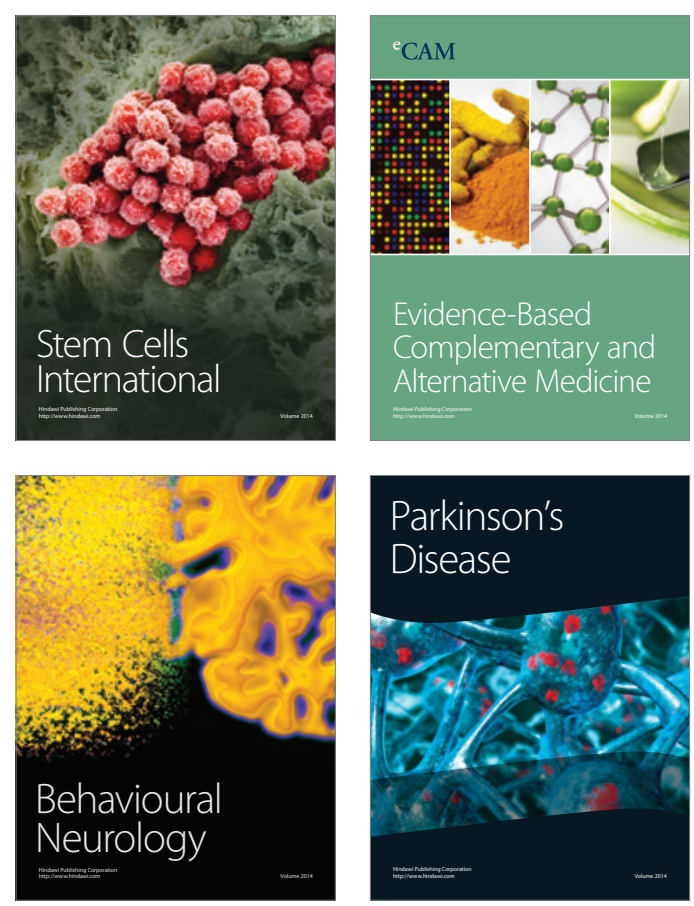

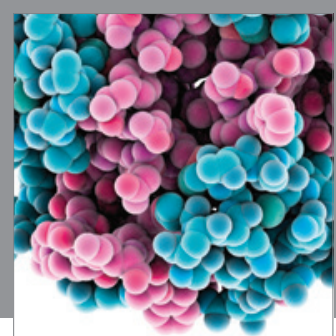

Journal of
Diabetes Research

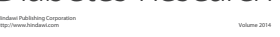

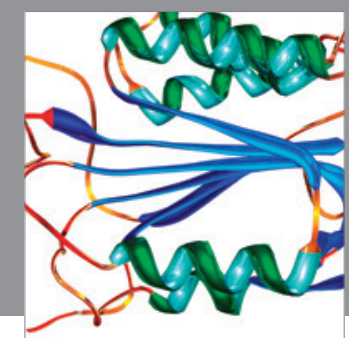

Disease Markers
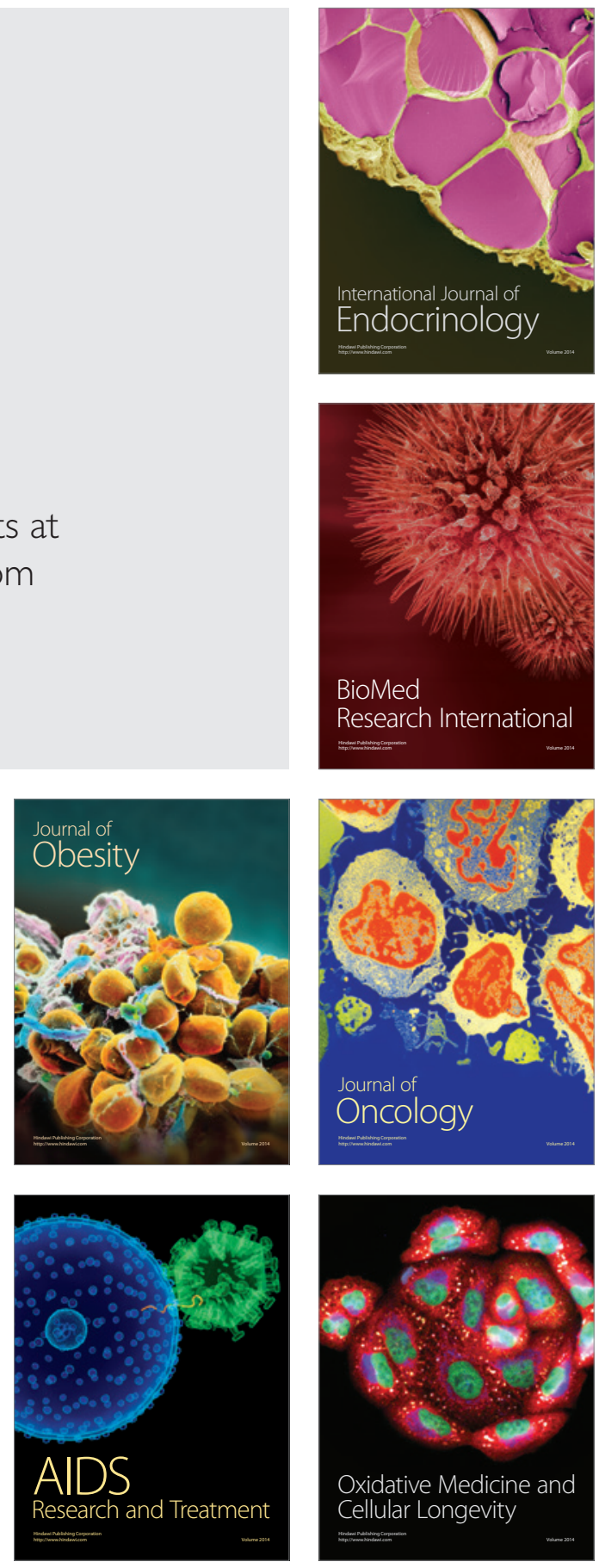